\title{
Improvement of Sub Base Soil Using Sand-Cement Stabilization
}

\author{
Md. Mahmud Hasan Mamun ${ }^{1,}$, Md. Firoz Mahmood Ovi², Farhana Akhter ${ }^{1}$, Saurav Barua ${ }^{1}$, \\ Mohiuddin Ahmed ${ }^{1}$, Thahomina Jahan Nipa ${ }^{1}$ \\ ${ }^{1}$ Department of Civil Engineering, University of Information Technology and Sciences, Dhaka, Bangladesh \\ ${ }^{2}$ Department of Civil Engineering, Ahsanullah University of Engineering and Technology, Dhaka, Bangladesh
}

Email address:

mmhmamun.ruet@gmail.com (Md. M. H. Mamun), sauravbarua02@gmail.com (S. Barua)

${ }^{*}$ Corresponding author

\section{To cite this article:}

Md. Mahmud Hasan Mamun, Md. Firoz Mahmood Ovi, Farhana Akhter, Saurav Barua, Mohiuddin Ahmed, Thahomina Jahan Nipa. Improvement of Sub Base Soil Using Sand-Cement Stabilization. American Journal of Civil Engineering. Vol. 4, No. 5, 2016 , pp. $241-246$. doi: 10.11648/j.ajce.20160405.15

Received: June 22, 2016; Accepted: July 15, 2016; Published: August 3, 2016

\begin{abstract}
Sand is the most available construction material in Bangladesh. Sand- cement stabilization is more cost effective and environment friendly for the construction of sub-base pavement layer in perspective of Bangladesh. The researchers conducted an investigation for the use of cement stabilized fine to medium sand in the construction of roads. Sands from various location such as-Mymensingh, Fajilpur Munshigonj and Sunamgonj are procured for this research work. Although Sunamgonj and Fajilpur sand are slightly expansive, those sand can be easily used as a substitute of unbounded material. According to the laboratory tests, all of the four types of sand have satisfied the criteria of sub-base layer strength on 14 days. The sand-cement material with 8 to $10 \%$ cement proved to be adequate for sub-base layers of heavily trafficked roads. It is observed that, sand sample with $8 \%$ cement mixes obtained from Fajilpur and Sunamgonj fulfill the specification requirements of sub-base layer for low traffic roads. On the basis of quantitative evaluation, appropriate sand-cement stabilization systems for roads need to be exercised and suggested.
\end{abstract}

Keywords: Sand, Sub Base, Cement, Soil Stabilization, Unbounded Material

\section{Introduction}

The purpose of a stabilized base or sub-base layer is to provide a transitional load-bearing stratum between the pavement layer, which directly receives the wheel loadings of vehicular traffic, and the underlying sub-grade soil [1]. Stabilized base or sub-base materials may be used to provide support for either flexible or rigid pavements, but are more frequently used with flexible pavements. The key to strength development in stabilized base or sub-base mixtures is in the matrix that binds the aggregate particles together. The strength of the matrix is affected by the cementations material used in the mixture [2]. The amount of cementations material in a stabilized base or sub-base mix usually ranges from 5 to 10 percent by weight of the mix. The main concentration of the research is to determine various sand grain analyses and which of them is perfect for stabilization with cement to use instead of bricks or stone chips. This research also indicates the stability of the road with perfect sand cement mixing proportions.

\section{Literature Review}

Materials that are available for the construction of pavements have a major influence on the design [3]. Under the Road Materials and Standard Study (RMSS) [4], a study funded by European Economic Community, an investigation was undertaken during 1993-1994 regarding the road construction materials of Bangladesh. Besides, some smallscale investigations were also carried out under particular road projects. However, the final design report of the Third Road Improvement Project [5] mentions that a number of road construction projects have created a shortage in quantity and fall of quality of available road construction materials, 
particularly stone materials. According to the RMSS, the major road building materials that are available in Bangladesh are sub-grade soils, bricks, boulder, gravel, sand, bitumen, emulsion, lime, cement, and geo-jute. Generally, clay, silt clay and clayey silt are the materials of embankments and sub-grade soils in Bangladesh. Fine aggregates are produced as a by-product during crushing of stones or boulders [6]. Specification of fine aggregate (consist of sand from Fajilpur, Sylhet) as per road structure manual of LGED shall conform to be composed of hard, tough and angular grains, Organic material content shall not exceed 5\%, Silt and other fine materials content shall not exceed $6 \%$ and it must be well graded from coarse to fine [7]. This material must not contain harmful impurities such as iron pyrites, coal, mica or other impurities which will affect the quality of concrete. In some specification instead of above grading the minimum fineness modulus (F. M.) is recommended for the sand is 0.8 , for concrete is 1.80 and for mortar is 1.50 as per road structural manual in LGED [7].

\section{Stabilized Road-Base}

The required specifications for sub-base and road-base, given in the Technical Specification booklet of different road projects, are described by the following items: grading, Atterberg limits, CBR, aggregate crushing value (ACV), ten percent fines value, bulk specific gravity, water absorption [8]. Crushed brick, which is a very common pavement material in Bangladesh, should be avoided in the road-base, instead, crushed rock should be used [9]. Considering the above, it may be suggested that there should be only one road-base and one sub-base. The recommended layer material for road-base should be crushed stone.

\section{Methodology}

In flexible pavement design, to reduce the cost of material cement stabilized sand can be used instead of other material such as brick. Besides sand with cement ( $8 \%$ \& 10\%) stabilization represents the durability of pavement layer. Greater F. M. value of sand with cement stabilization is suitable for high volume traffic roads. The sands were collected from different parts of Bangladesh. Those were collected from Gojaria Chor (Munshigonj), Fajilpur sand (Sylhet), Sunamgonj sand (Sylhet), white sand from Mymensingh, and Kortoa river sand (Comilla) and Dumar sand (Rangpur). The experiments that were done in this experiments are Sieve analysis test and Compressive strength test.

\subsection{Sieve Analysis}

Sieve analysis is a procedure used to find the particle size distribution of a granular material [10]. Sieve analysis is for coarse grained soils which can easily pass through a set of sieves. In this study, sieve analysis is done for fine grained sand. The sand is sieved through a set of sieve. The material retained on the sieves were collected. It is then sieved through a set of sieve of the size \#8 (2.36 mm), \#10 (2.00 $\mathrm{mm})$, \#16 (1.18 mm), \#30 (0.6 mm), \#40 (0.425 mm), \#50 $(0.355 \mathrm{~mm}), \# 100(0.150 \mathrm{~mm}), \# 200(0.075 \mathrm{~mm})$ and pan. The material retained on the each sieve was collected and weighed. The material that would have been retained on the pan is equal to the total mass of the soil minus the sum of the masses of material retained on all sieve.

\subsection{Compressive Strength Test}

This method describes the procedure for making and curing compression test specimens from fresh concrete and for determining the compressive strength of the mortars using $2 " \times 2 "$ cube specimens. Materials used for this test are cement, fine to medium graded sand and water. Use water cement ratio of $0.85,0.9,0.7$ and 0.82 for the sand of Sunamgonj, Munshigonj, Fajilpur and Mymensingh respectively. Place required amount of water in dry mixing. Add the cement to the water and mix for $30 \mathrm{sec}$. Then added the sand and mix for a while. Place the mold on a firm, level surface. Form the test sample by placing concrete in the mold in three layers of approximately equal volume. Rod each layer with 25 strokes of the tamping rod. Store the specimen undisturbed for 24 hours at $15^{\circ} \mathrm{C}$ to $27^{\circ} \mathrm{C}$. Remove the test specimen and transfer carefully to the place of curing and testing. Place the specimen in the UTM machine and slowly bring the blocks to bear on the specimen without shock until failure occurs. Operate the machine at a constant rate within the range of 1 mm per minute. Than mold are crashed and cracks developed over the surface of the body.

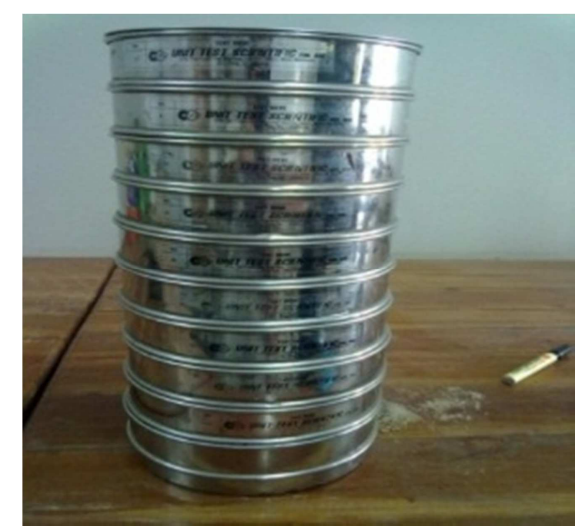

Figure 1. Set of sieve in lab.

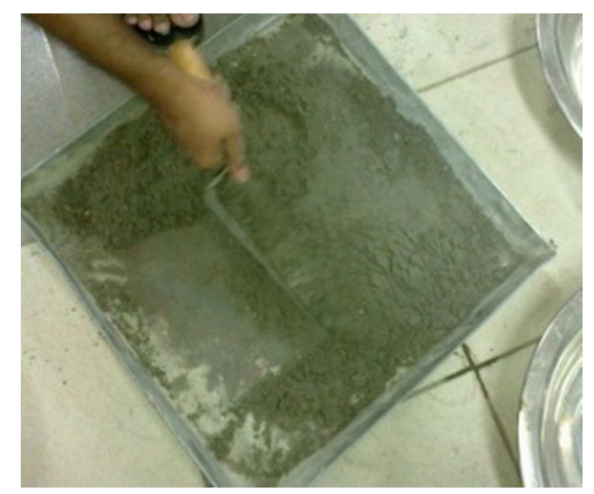

Figure 2. Preparation to mix samples. 


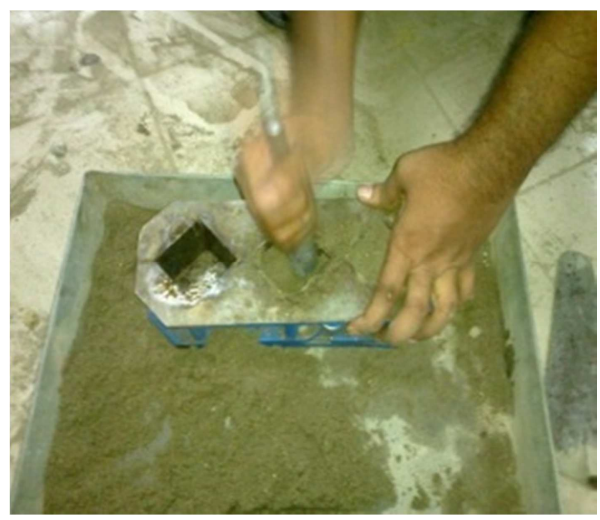

Figure 3. Tampering the layer with rod.

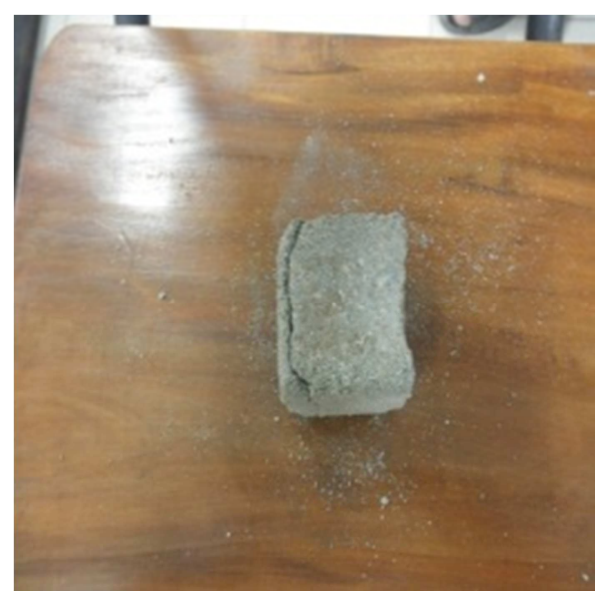

Figure 4. Cracks develop after crashing.

\section{Data Analysis}

\subsection{Sieve Analysis of Different Type of Sands}

Four types of sand selected in the basis of their F. M. value. For our laboratory experiment there are two sands of higher FM value than 2, one sand contains of lower FM value and other sand contains medium F. M. value. There sieve analysis result are given below.

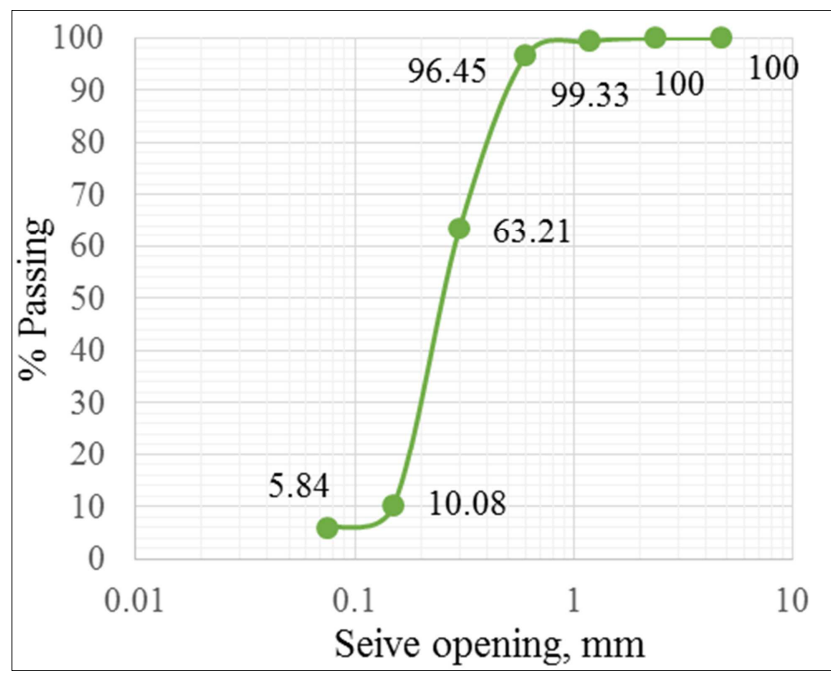

Figure 5. Gradation curve of Munshigonj sand.

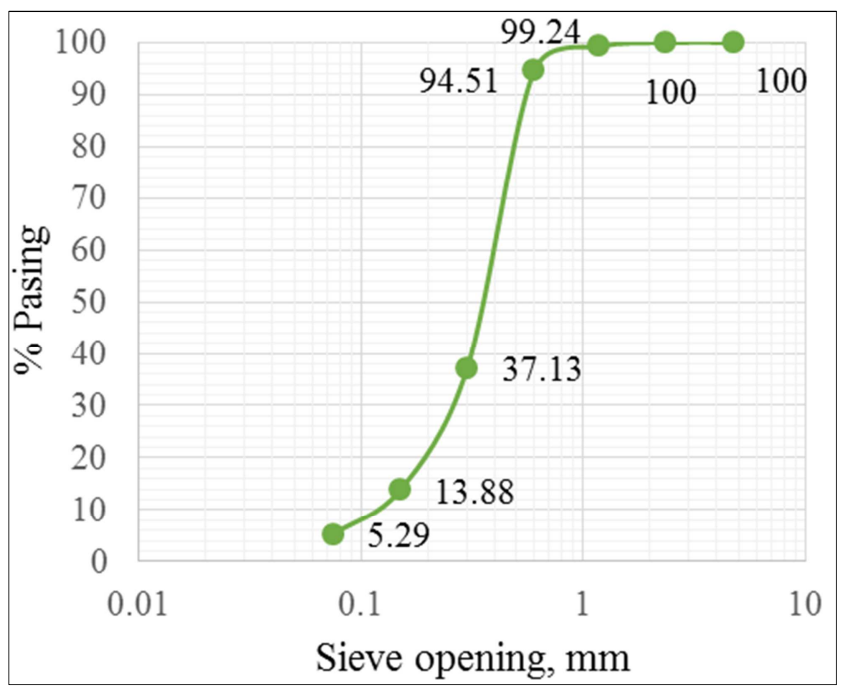

Figure 6. Gradation curve of Mymensingh sand.

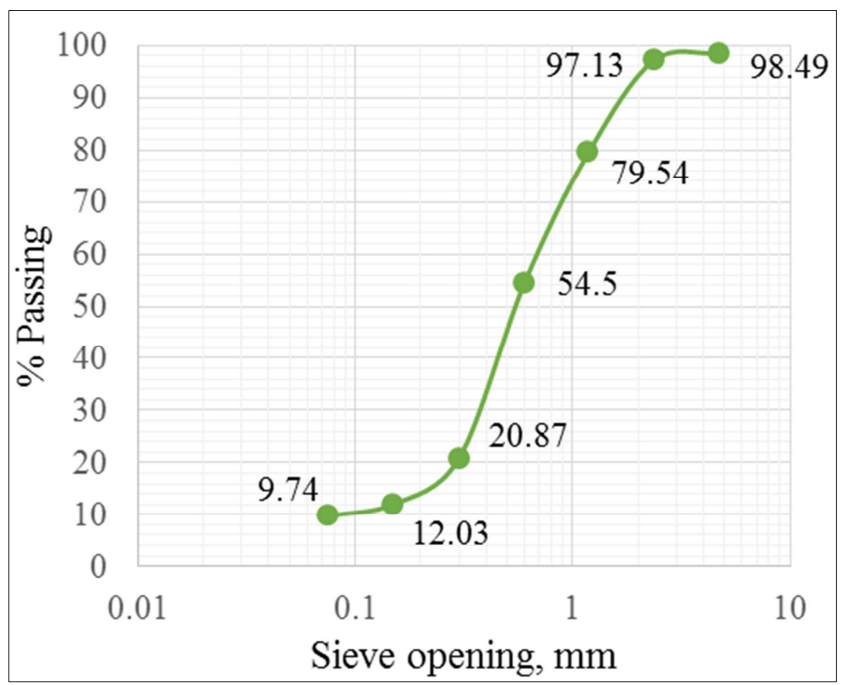

Figure 7. Gradation curve of Fajilpur sand.

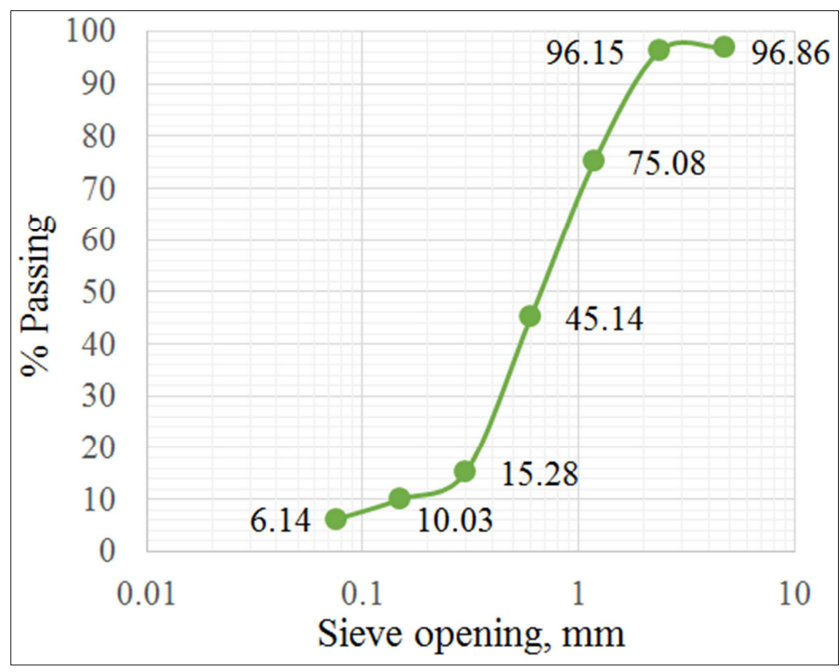

Figure 8. Gradation curve of Sunamgonj sand.

F. M. value obtained in Sunamgonj is 2.61. The sand is well graded sand and contains the highest F. M. value and the 
shape of the gradation curve also similar to English alphabet S. F. M. value is 2.37 and sample is well graded sand. Well graded sands are desirable for making concrete, as the space between larger particles is effectively filled by smaller particle to produce a well-packed pavement. The sand of Munshigonj has F. M. value 1.29, uniform and well graded sand. F. M. value of Mymensingh sand is 1.55 . The sample is uniformly graded sand among the four types of sand.

\subsection{Compressive Strength Analyses}

The mechanical strength of hardened sand-cement is the property of this material which is perhaps, the most important one for its structural use. Tests for strength are not made on a neat sand-cement paste because of difficulties in mounding and testing with a consequent large variation in result. Following four types of graph shows the average value of compressive strength $(8 \%$ cement $)$ of Munshigonj, Mymensingh, Sunamgonj and Fajilpur sand.

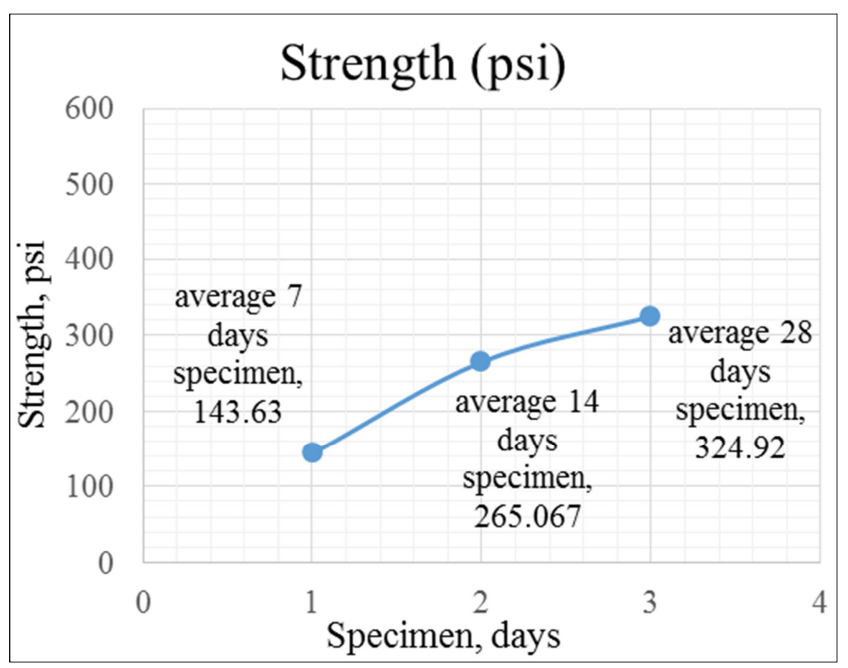

Figure 9. Average compressive strength of Munshigonj sand.

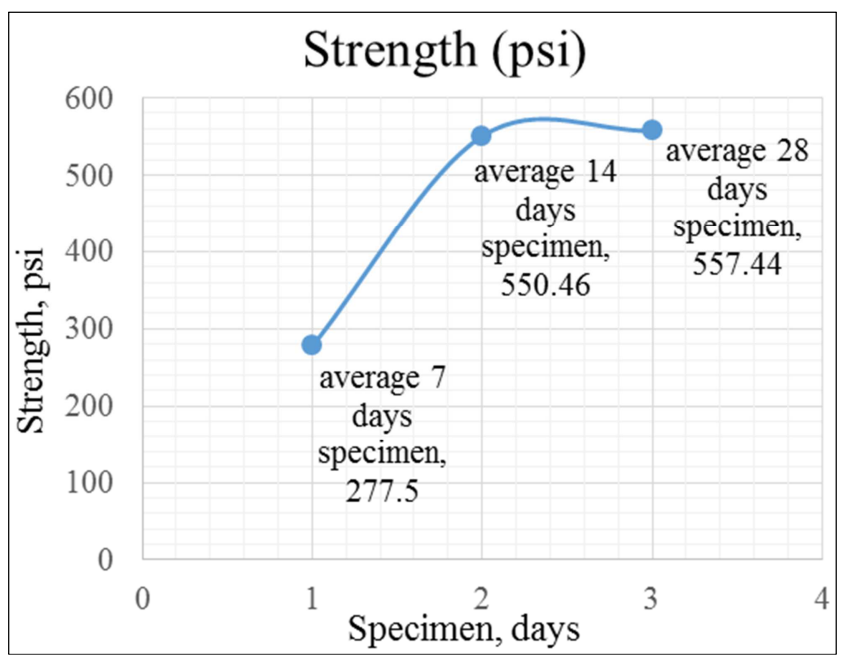

Figure 10. Average compressive strength of Sunamgonj sand.

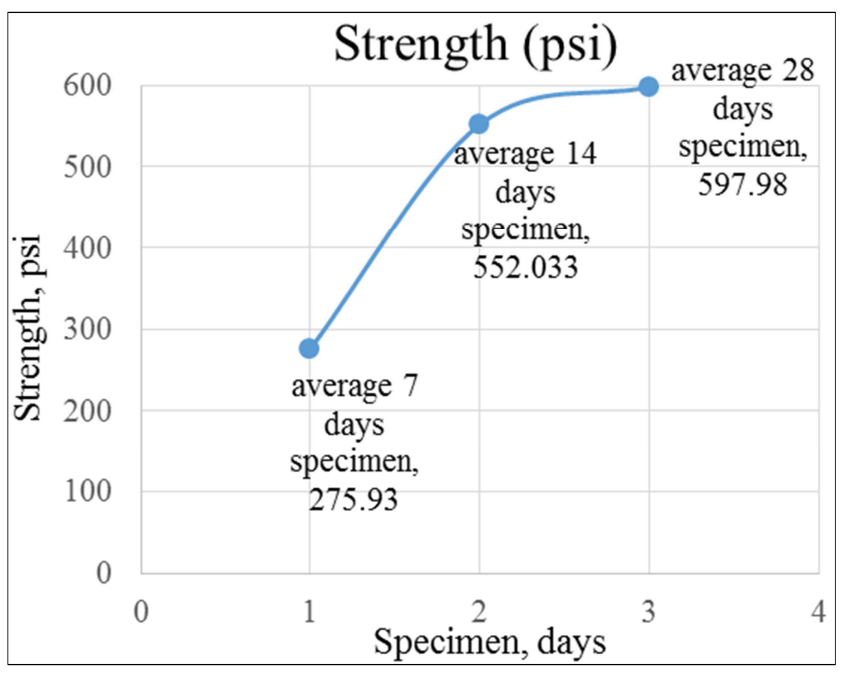

Figure 11. Average compressive strength of Fajilpur sand.

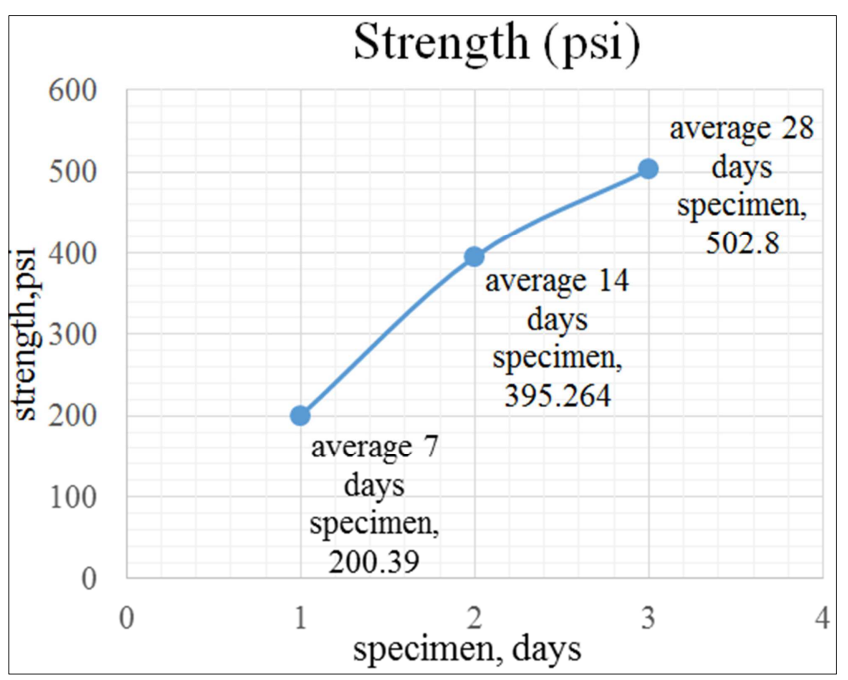

Figure 12. Average compressive strength of Mymensingh sand.

The FM value of Sunamgonj, Fajilpur and Mymensingh sand is higher side that's why the strength also in the higher side compared to the other sands. The strength gained by the 7 days specimen would be suitable for road pavement to replace brick in sub-base. On the other hand, the FM value of Munshigonj sand are low that's why the strength also in the lower side compared to the other sands. 7 days strength is not suitable for road pavement to replace brick.

\subsection{Comparison of Strength Between $8 \%$ and $10 \%$ Cement}

These bar charts illustrate comparison of strength with four types of sand for 7 days. From the diagram, yellow color presents the $10 \%$ cement and purple color shows the $8 \%$ cement. In general, the values of 7 days fluctuate very little among the four types of sand. 


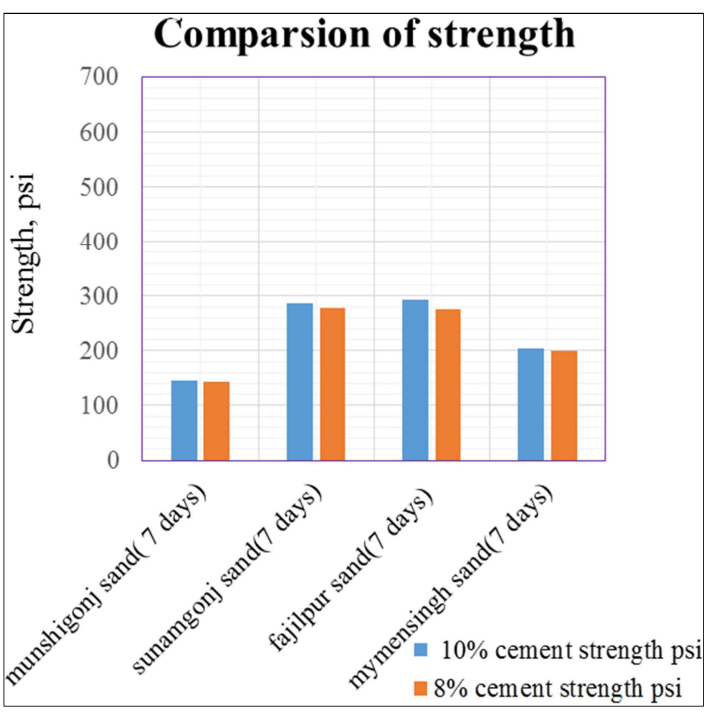

Figure 13. Comparison of strength in 7 days.

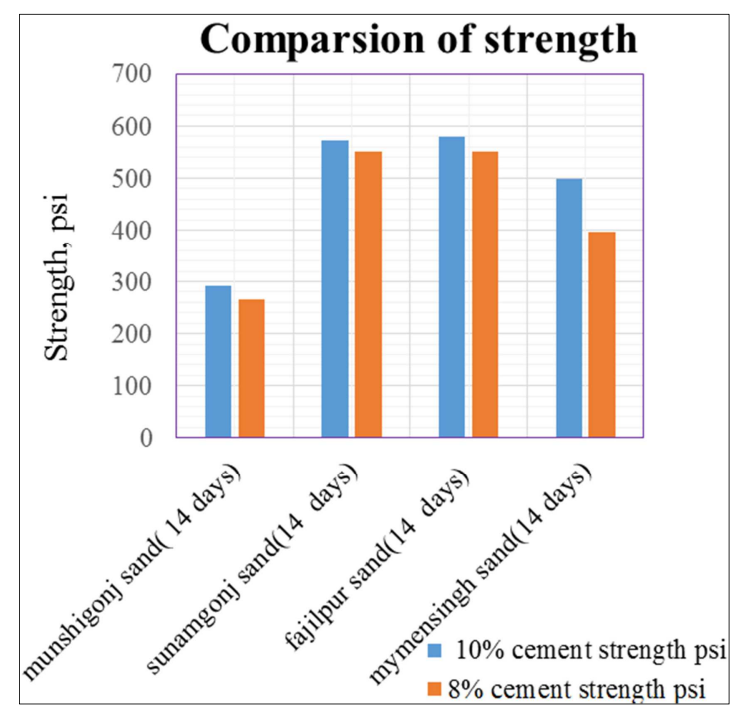

Figure 14. Comparison of strength in 14 days.

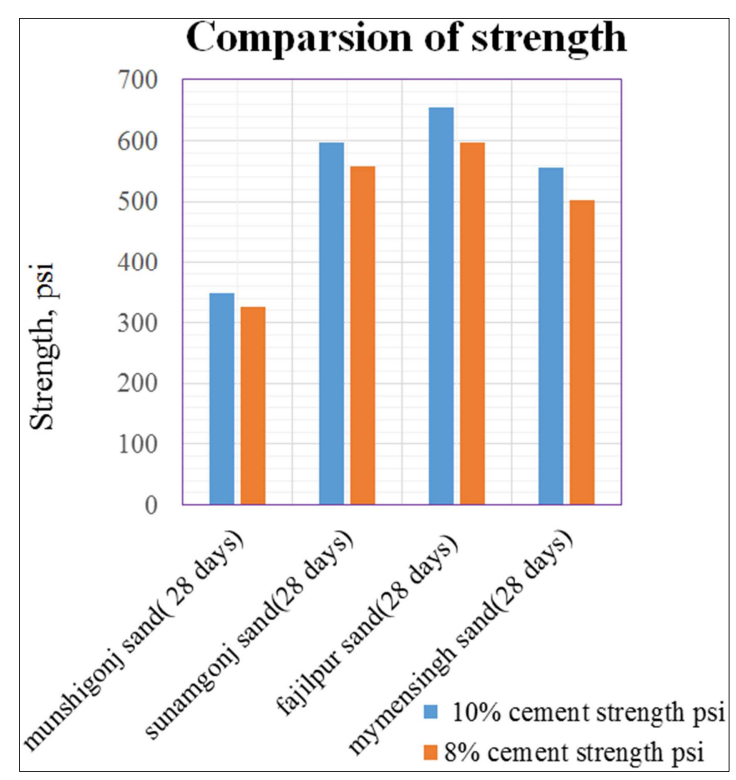

Figure 15. Comparison of strength in 28 days.
From the above bar diagrams, among the four types of sand such as Munshigonj, Mymensingh, Sunamgonj and Fajilpur. Sunamgonj and Fajilpur sand meet the compressive strength requirement of sub-base pavements layer on 7 days. It also shows uniformly well graded characteristics property. On the other hand, another two types of sand could not satisfy the strength requirement on 7 days. But they also meet 14 days strength requirement. Moreover, 7 days strength with less quantity of cement (8\%) is great aspire for this research. Using sand with $10 \%$ cement is more expensive because cement is costly binding material. In conclusion it is possible to speculate that sand of Sunamgonj and Fajilpur is cogently used in sub-base layer with ( $8 \%$ cement); which is assuaging the cost of construction.

\section{Conclusion}

In Bangladesh sand is the most available construction material. In sub-base pavement layer, sand- cement stabilization is more cost effective than bounded material and is more environment friendly in perspective of Bangladesh. Although Sunamgonj and Fajilpur sand is slightly valuable in Bangladesh. This type of sand can be easily used as a substitute of unbounded material. This research work is done based on sand-cement stabilization in sub-base pavement layer by Sunamgonj, Fajilpur and Mymensingh and Munshigonj sand. According to this work, four types of sand have satisfied the criteria of sub-base layer strength on 14 days. But it is more expensive and time consuming for the stabilizing the sub-base layer with $10 \%$ cement. It can be seen that, only Fajilpur and Sunamgonj sand sample fulfill the specification that requires in sub-base layer on 7 days with $8 \%$ cement for low traffic loads. However, for the pavement of high traffic loads stabilization based on sand with $10 \%$ cement is recommended. It is recommended that future research can mix more than one types of sand for the stabilization and find out the compressive strength for that mixed sand sample. On the other hand, sand with higher F. M. value and lower F. M. value can mix with different percentages. Besides, another binding material and different types of admixtures may be used as a substitute of cement which alleviates the cost of construction. In situ test may be performing during the construction period and natural decomposing waste may be juggle with sand. In near future trial of different binding material may be mixed with sand to perform field test.

\section{References}

[1] AASHTO Guide for Design of Pavement Structures. American Association of State Highway and Transportation Officials, Washington, DC, 1993.

[2] Soil Stabilization in Pavement Structures. A User's Manual. Volumes 1 and 2. Federal Highway Administration, Report No. FHWA-IP-80-2, Washington, DC, 1980.

[3] Formerly Federal-aid Policy Guide Non-Regulatory Supplement NS 23 CFR, Part 626, April 8, 1999, Transmittal 25. 
[4] Roads and Highways Department (1998), Design Report, Volume 1, Main Report, Rehabilitation of Dhaka-Sylhet Road, Roads and Highways Department, Dhaka, Bangladesh.

[5] Roads and Highways Department (2000a), Final Design Report, Third Road Improvement Project, RHD, Dhaka, Bangladesh.

[6] Roads and Highways Department, Bangladesh (2002a), Proposed Pavement Design Standards for Roads \& Highways Department, Dhaka, Bangladesh.
[7] Quality control manual, LGED, September 2005.

[8] Islam, R (2004): “Civil Engineering Materials-01". Revised version, Published in Dhaka, Bangladesh Technical Education Board (CT113)

[9] Hornbostel, C (1991): "Construction Materials". 2nd Edition. Published in U.S.A, John Wiley and Sons, Inc.

[10] Donald Mcglinchey (2005), "Characterisation of bulk solids", CRC Press. (https://en.wikipedia.org/wiki/Sieve_analysis) 